\title{
RELAÇÕES DE “NÃO CUIDADO” DE ENFERMAGEM EM UMA EMERGÊNCIA: QUE CUIDADO É ESSE?
}

\author{
"Non-care" nursing relationships in an emergency room: What care is this? \\ Relaciones de "no asistencia" de enfermería en caso de emergencia: ¿Qué atención es \\ esa?
}

Maria Aparecida Baggio ${ }^{1}$

Giovana Dorneles Callegaro²

Alacoque Lorenzini Erdmann ${ }^{3}$

\section{RESUMO}

Este estudo qualitativo objetivou compreender as relações de "não cuidado" de enfermagem significadas por pacientes de um serviço de emergência hospitalar. Foram entrevistados 19 indivíduos pertencentes à faixa etária de 35 a 85 anos, provenientes da capital e de cidades do interior do estado de Santa Catarina. Os dados foram submetidos à análise de conteúdo e interpretados na ótica do pensamento complexo. Destacam-se, neste artigo, os significados das relações de "não cuidado" de enfermagem, apresentadas em duas categorias: Não informação, atenção e assistência de enfermagem devida; Comunicação como expressão de "não cuidado". Importa a sensibilidade por parte da enfermagem no seu processo de cuidar, com vistas à promoção da interação profissional-paciente, sendo este reconhecido e respeitado como sujeito de cuidado, como preconiza o código de ética profissional. Urge à enfermagem o avanço na forma de pensar e agir as/nas relações estabelecidas no espaço organizacional em saúde.

Palavras-chave: Cuidados de Enfermagem. Enfermagem em Emergência. Serviços Médicos de Emergência.

\begin{abstract}
The objective of this qualitative study was to better comprehend the "non-care" nursing relationships as signified by patients of a hospital emergency service. Nineteen adult individuals between the ages of 35 and 88 years old who live in the capital city and rural cities in the state of Santa Catarina were interviewed. The data was submitted to content analysis and interpreted under the perspective of complex thought. The significances of the "non-care" nursing relationships are highlighted in this article, and presented in two categories. Necessary nursing noninformation, care, and assistance; Communication as an expression of "non-care". Sensibility on behalf of nursing is important concerning the aspects which involves the care process, seeking the promotion of professional-patient interaction, given that the patient is recognized and respected as the subject of care, as is extolled in the professional code of ethics. We urge nursing to advance in its form of thinking and acting in/towards established relationships in the organizational realm of health care.
\end{abstract}

Keywords: Nursing Care. Emergency Nursing. Emergency Medical Services.

\section{Resumen}

Este estudio tuvo como objetivo entender las relaciones de "no asistencia" de enfermería destinadas al cuidado de los pacientes en una sala de emergencia del hospital. Entrevistamos 19 personas con edades entre 35 y 85 años, de la capital y de ciudades del interior de Santa Catarina. Los datos fueron sometidos a análisis de contenido e interpretados desde la perspectiva del pensamiento complejo. Se destaca, en este artículo, los significados de las relaciones de "no atención" de enfermería, presentadas en dos categorías: No hay información, atención y cuidados adecuados de enfermería; La comunicación como una expresión de "no atención". Es la sensibilidad de la enfermería como un proceso de cuidado, a fin de promover la interacción profesional-paciente, que es reconocida y respetada como sujeto del cuidado, según lo recomendado por el código de ética profesional. Cabe a enfermería avanzar en su manera de pensar y de actuar las/en las relaciones establecidas en el espacio organizacional de salud.

Palabras clave: Atención de Enfermería. Enfermería de Urgencia. Servicios Médicos de Urgencia.

\footnotetext{
Enfermeira. Doutoranda em Enfermagem pelo PEN da UFSC. Bolsista do CNPq. Membro do Grupo de Estudos e Pesquisas em Administração de Enfermagem e Saúde (GEPADES) na UFSC. Florianópolis- SC. Brasil. E-mail: mariabaggio@yahoo.com.br, ${ }^{2}$ Enfermeira. Membro do Grupo GEPADES na UFSC. Florianópolis- SC. Brasil. E-mail: gikac@bol.com.br, ${ }^{3}$ Enfermeira. Doutora em Enfermagem. Professora Titular do Departamento de Enfermagem da UFSC. Líder do GEPADES. Pesquisadora 1 A do CNPq. Florianópolis- SC. Brasil. E-mail: alacoque@newsite.com.br.
} 


\section{INTRODUÇÃO}

0 investimento na educação e no aperfeiçoamento dos profissionais atuantes nos serviços de emergência pelos hospitais nos Estados Unidos da América ocorreu a partir da década de 1970 e, no Brasil, da década de 1980, visando qualificar 0 atendimento ao paciente vítima de trauma nos serviços de emergência, o qual era superficial e com debilidades. No Brasil, a ênfase dada à capacitação dos profissionais possibilitou a criação, em 1985, da Sociedade Brasileira dos Enfermeiros do Trauma (SOBET), a primeira associação de enfermagem especializada em trauma, ${ }^{1}$ cuja atuação contribui para a redução das taxas de mortalidade e sequelas incapacitantes, tanto temporárias quanto definitivas.

Um hospital que atende urgências e emergências deverá ter estrutura adequada de atendimento, com equipe multiprofissional, recursos técnicos mínimos e funcionamento ininterrupto, garantindo todas as manobras de sustentação da vida, com continuidade da assistência no local ou em outro nivel de atendimento referenciado. A Resolução 1451/95 do Conselho Federal de Medicina define urgência como "a ocorrência imprevista de agravo à saúde com ou sem risco potencial de vida, cujo portador necessita de assistência médica imediata", e emergência como "a constatação médica de condições de agravo à saúde que impliquem risco iminente de vida ou sofrimento intenso, exigindo, portanto, tratamento médico imediato". ${ }^{2}$ Nessa lógica, o atendimento deve ser pensado conforme o nível de complexidade e necessidades específicas do sujeito em condição crítica de saúde, otimizando o uso dos recursos materiais e de pessoal disponíveis. ${ }^{3}$

Quanto aos recursos humanos, o profissional atuante em serviço de emergência, ao estabelecer relação com o paciente, deve escutar sua queixa, seus medos e expectativas; identificar riscos e vulnerabilidade; oferecer resposta e condução adequada ao problema de forma pactuada com o paciente, conjugando as necessidades deste e as possibilidades do serviço; conduzindo, dessa forma, um encaminhamento responsável e resolutivo do problema identificado, de maneira ética e segura. ${ }^{3}$

Compete ao profissional de enfermagem de emergência, na interação que estabelece com o paciente, propiciar o cuidado uni e multidimensional, segundo o pensamento complexo, buscando contemplar as particularidades e multiplicidades do ser. 0 pensamento complexo possibilita uma nova forma de contemplar a realidade que permeia o espaço do cuidar em enfermagem, desvinculando-se do pensamento reducionista, embasado na neutralidade de valores, que contempla o ser humano de forma fragmentada, isolada e unilateral. Assim, 0 pensar complexo tem o propósito de unificar, clarificar e contextualizar a relação do ser humano com si próprio, com o outro e com o universo, bem como expressar as singularidades e pluralidades do ser. ${ }^{4}$

Entende-se o cuidado como um elemento imprescindível nas relações humanas para o bem-estar, manutenção da saúde e da própria vida; é um elo entre seres cuidados e seres cuidadores, que fortalece e potencializa o processo de recuperação na condição de saúde-doença, inter-relacionando os demais processos dinâmicos manifestos no ato de cuidar. No entanto, quando o cuidado não acontece pode ocasionar ressonâncias negativas para o indivíduo.

Entendemos que é preciso avançar na forma de pensar e de agir na relação estabelecida com o outro - paciente no espaço organizacional em saúde, em especial o da emergência, pelos profissionais de enfermagem e da saúde em geral, cujo cuidado, em condições distintas, parece não atender às expectativas deste outro.

A realidade do atendimento em saúde, frequentemente divulgada pela mídia, denuncia a escassez de leitos e profissionais para atender à demanda e às necessidades mínimas da população, cuja qualidade do cuidado é comprometida. 0 serviço de emergência, entendido como principal porta de entrada das instituições terciárias em saúde, agrega e expõe problemas oriundos da rede básica e da escassez de leitos das unidades de internação e das unidades de tratamento intensivo (UTIs), que não absorvem os atendimentos gerados, superlotando as emergências.

Cabe ressaltar que a superlotação das emergências é uma realidade dos serviços públicos e também dos privados, tanto no Brasil como no exterior, em países em desenvolvimento ou desenvolvidos..$^{5-6}$ Outra questão a destacar é que o quadro de profissionais não acompanha a mesma elevação da busca espontânea de atendimentos pelos pacientes nos serviços de emergência.

Na literatura, atualmente, encontra-se uma riqueza de estudos que discorrem acerca do cuidado, seus significados e dimensões, relacionados ao ser cuidado e seres cuidadores, os quais, indiscutivelmente, contribuem para a melhoria da assistência, do cuidado, do ensino, pesquisa e gerenciamento em enfermagem. Em contrapartida, o "não cuidado", principalmente na voz dos pacientes, parece ser ainda pouco investigado nas pesquisas em enfermagem. ${ }^{7-8}$

Por essas razões, consideramos importante dar voz aos pacientes em resposta às inquietações: Ocorrem relações de "não cuidado" de enfermagem em um serviço de emergência hospitalar junto aos sujeitos internados ou em observação, quando questionados sobre o significado das relações de cuidado de enfermagem? Se existem, que significados são atribuídos por esses sujeitos? Assim, objetivamos compreender as relações de "não cuidado" de enfermagem significadas por pacientes de um serviço de emergência hospitalar.

\section{METODOLOGIA}

Trata-se de um recorte de um de estudo qualitativo exploratório e descritivo, desenvolvido em um hospital público estadual terciário de Santa Catarina, no serviço de emergência. 0 projeto de pesquisa, intitulado "O significado das relações 
de cuidado de enfermagem em uma unidade de emergência na percepção do ser humano cuidado" foi aprovado pelo Comitê de Ética em Pesquisa com Seres Humanos da instituição em que os dados foram coletados, sob o número de protocolo 017/ 07, sendo respeitados os critérios éticos de pesquisas envolvendo seres humanos, conforme a Resolução $196 / 96^{9}$ do Conselho Nacional de Saúde, em todas as etapas da pesquisa.

Foram participantes 19 indivíduos adultos, que, conforme critérios de inclusão, estavam internados ou em observação no período da coleta dos dados, provenientes da capital e de cidades do interior do estado de Santa Catarina e que, esclarecidos acerca do processo investigativo e dos objetivos, aceitaram participar voluntariamente do estudo, mediante a assinatura do Termo de Consentimento Livre e Esclarecido. A faixa etária dos participantes foi de 35 a 85 anos, todos lúcidos e comunicativos, cuja condição clínica permitiu a participação sem danos ou prejuízos à sua saúde física, não havendo exclusão de sujeitos da coleta dos dados. 0 número de participantes foi alcançado pela saturação dos dados qualitativos e, para preservar a sua identidade, utilizou-se a letra $\mathrm{P}$, seguida do número ordinal correspondente à ordem da entrevista na identificação das falas, assim apresentadas a título de exemplo: P.1, P.2, P.3...

A coleta de dados foi realizada no período de setembro a novembro de 2007, uma vez por semana (entre segunda e sexta-feira), no turno vespertino, com realização de entrevistas semiestruturadas, registradas por meio de gravador digital de voz, e realização de observação não participante, com anotações de campo do comportamento dos entrevistados e dos aspectos inerentes ao ambiente do estudo. Salienta-se que não ocorreram intercorrências durante a coleta dos dados no ambiente em que se encontravam os participantes do estudo, internados ou em observação.

Os dados foram submetidos à análise temática de conteúdo, ${ }^{10}$ seguindo três momentos distintos: primeiramente, foi realizada uma leitura de contato dos dados coletados; em seguida, realizaram-se várias leituras do mesmo material visando a maior aprofundamento das informações e consequente busca dos significados nas falas dos sujeitos, sendo recortadas do texto as palavras-chave ou frases de significado dos conteúdos manifestos para a formação das unidades de significados; posteriormente, essas unidades de significados foram classificadas e agregadas, sendo, então, definidas e interpretadas as categorias que orientam as especificações dos temas, sob o olhar da complexidade. ${ }^{4}$

Tendo atingido o objeto focado no projeto inicial, o qual seja de compreender as relações de cuidado significadas por pacientes de um serviço de emergência hospitalar, também foram identificados a partir das falas dos participantes os significados das relações de "não cuidado". Por entendermos que são informações de importante significado para reflexão sobre as relações estabelecidas no cotidiano do trabalho da enfermagem, apresentaremos a seguir, como produto deste artigo, a análise compreensiva e a discussão acerca das relações de "não cuidado" de enfermagem significadas por pacientes de um serviço de emergência hospitalar.

\section{ANÁLISE E DISCUSSÃO DOS RESULTADOS}

0 serviço de emergência estudado é referência regional para atendimento de média e alta complexidade; atendendo, em média, 300 pacientes/dia; possui 22 leitos para internação e 40 para observação; conta com 12 técnicos e auxiliares de enfermagem e 3 enfermeiros por plantão de 6 horas.

Do processo de categorização dos discursos dos sujeitos internados ou em observação neste cenário, emergiram as categorias Não informação, atenção e assistência de enfermagem devida; Comunicação como expressão de "não cuidado", apresentadas e analisadas a seguir.

\section{Não informação, atenção e assistência de enfermagem devida}

Os participantes, em seus depoimentos, clarificam a insatisfação e o descontentamento quanto às ações dos profissionais de enfermagem, que, na relação estabelecida com o outro, revelam a não informação e atenção, compreendidas como "não cuidado" de enfermagem, conforme se confere nas falas a seguir:

A gente vai e faz uma pergunta: que horas tem mais soro? Elas [se referindo à enfermagem] não respondem. Edepois dizem: depois, na hora vamos ver! [...] Uma manda falar com a outra [se referindo à enfermagem]. Não custa uma delas vir e falar com o paciente. A gente chama porque precisa, jamais vai lá incomodar a enfermeira. Agora, se tá no soro, e tá sangrando, a gente tem que chamar. $\dot{E}$ como você vê aí ó: mais de duas horas esperando! [...] se a pessoa tá passando mal, a gente chama e eles pedem pra esperar... Se a gente chama éporque precisa! Se não precisasse, não chamaria! Ontem eu chamei e fui mal atendido. [...] 0 soro tava sangrando, as técnicas estavam, mas não me deram bola. Daí, nós mesmos tivemos que tirar! Era pra tirar 11 h30, quando eram 14h da tarde pegamose tiramos o soro. Custa vir aqui, colocar uma tampinha e tirar o soro? (P.4)

A espera, por enquanto tem que esperar! Não saber de nada! Se vai ser atendido e se não vai. Você já vem de fora [do interior do estado] pensando: por que te mandaram vir? Se não tinha vaga, então não mandasse! Eu fiquei chateada [...] Você tem direito de saber, porque, afinal, o doente tem direito de saber tudo! Devem explicar com calma [...] (P.1). 
Deve ser profissional, responder e prestar atenção no outro, responder bem [...] dar mais atenção pra gente, dar informações, com mais respeito [...]. Elas ficam correndo pra fazer de conta que tem serviço, eu entendo também, mas ninguém vai morrer pra responder dois minutos [...] (P.2).

Nas ações desenvolvidas pela equipe de saúde, a informação e a atenção ao paciente e ao que estiver relacionado a ele são indispensáveis para que ele se sinta devidamente cuidado. Importa para os participantes que suas dúvidas sejam respondidas e esclarecidas e que, quando requerem atenção do profissional, sejam atendidos. Ademais, esclarecem que solicitam quando realmente há necessidade do cuidado profissional, denotando a preocupação em não demandar desnecessariamente o tempo e as ações da enfermagem, no sentido de não serem um incômodo.

No entanto, revelam o descontentamento com a pouca atenção dispensada e a demasiada espera por atendimento em condição de particular necessidade. Ainda salientam em seus depoimentos a transferência de responsabilidade observada entre os profissionais, seja para sanar uma dúvida, seja para realizar um procedimento de competência destes. Sobretudo, parece faltar calma e respeito nas atitudes para com o outro de parte da enfermagem.

Dessa forma, confirma-se a insatisfação dos participantes em relação à conduta da enfermagem, que neste estudo revela condições de "não cuidado". Ora, não seria a enfermagem uma profissão de cuidado? Como compreender o comportamento dos profissionais da enfermagem, que possuem direitos mas também deveres e responsabilidades para com os pacientes, conforme o código de ética profissional? Que cuidado éesse?

A enfermagem é reconhecida por ser uma profissão de cuidado. Seu código de ética ${ }^{11}$ assegura a validação das ações do cuidar. Nesse sentido, estes profissionais necessitam dispor de meios para exercer seu trabalho de forma correta e digna, ou seja, ser capazes de reconhecer e valorizar a percepção do outro, aliado ao respeito e a ética no cuidado.

Assevera-se que, "além da habilidade técnica, é imprescindível que os profissionais de enfermagem também detenham conhecimentos a respeito das normas regulamentadoras do exercício, dos direitos e das obrigações profissionais. Contudo, esse conhecimento não deve substituir as dimensões ética e moral que permeiam as ações desses profissionais", ${ }^{12}$ nem mesmo o seu compromisso maior, que é 0 cuidado do outro, como um ser complexo, pois é, ao mesmo tempo, biológico, psíquico, social, afetivo e racional; pensante e consciente de si; que traz em si sua irredutível individualidade/ coletividade, autonomia/dependência/interdependência; que depende de outros para a sua autonomia e sobrevivência. ${ }^{4}$

Identifica-se neste estudo, de acordo com o código de ética dos profissionais de enfermagem, ${ }_{11}^{11}$ o descumprimento de alguns deveres no exercício da profissão, o que relatos dos pacientes apontam, em relação às ações e atitudes dos trabalhadores, à não prestação de adequadas informações e de assistência devida, como, por exemplo, não retirar o soro que extravasou sangue mediante solicitação do paciente e familiar. Ainda, o não cuidado envolve ocorrências de falhas éticas no que tange ao relacionamento, a formas de comunicação e atenção ao paciente, seus familiares e outros, que não estão sendo realizadas de forma adequada e satisfatória pela equipe.

Dentre as falhas éticas manifestadas pelos participantes, a prioria população idosa, identificam-se a falta de atenção e o não cumprimento total, ou cumprimento em parte, do Estatuto do 1 doso ${ }^{13}$, compreendidos como condição de "não cuidado". A equipe médica, na instituição estudada, apresenta-se quantitativamente insuficiente para realizar o atendimento preferencial imediato e individualizado, bem como as instalações físicas não oferecem acomodação para todos os que buscam atendimento, em especial para idosos, assegurado por lei.

[..] é pouco médico, principalmente se é idoso, um médico só pra idoso, é a prioridade idoso. Então eu acho que devia ser separado de outros casos, porque por ser idoso já tem mais dificuldade, tem que ter atenção especial (P.5).

[..] tinha que melhorar o lugar onde você vai ser atendido, umas senhoras em pé, idoso em pé...? (P.1).

A falta de informação, um direito do paciente e um dever do profissional, que acomete a maioria dos participantes provoca angústia e leva a que fiquem sem entender o que está, realmente, acontecendo, seu diagnóstico e formas de tratamento propostas, o que, por sua vez, também conduz à insegurança em relação às ações profissionais, visto que parecem não respeitar o direito de conhecimento acerca dos eventos que envolvem o seu ser e o que está lhes sendo reservado durante o processo de hospitalização.

0 aneurisma de aorta é considerado uma patologia grave, que inspira cuidados médicos e de enfermagem, cujo grau de mortalidade é extremamente elevado. Portadora do diagnóstico de aneurisma de aorta abdominal, uma paciente foi transferida de um hospital de um município do interior do estado de Santa Catarina para um hospital de referência em cardiologia, na capital, para ali realizar tratamento cirúrgico. Todavia, esta paciente, que se encontra internada na emergência, ciente da gravidade e dos riscos da sua condição, manifesta-se apreensiva, nervosa, angustiada e triste por não obter informações acerca da esperada cirurgia. São condições de "não cuidado" semelhantes às dos demais participantes, que apontam a demora no atendimento, a falta de informação, 
atenção e assistência. As inúmeras transferências entre diversos serviços de saúde de referência e contrarreferência ${ }^{14}$ e dentro da própria emergência causam indignação e revolta à paciente, que, emocionada, revela sua insatisfação, incertezas, sentimentos e a sensação de abandono que a perturbam:

[...] fiquei muito tempo esperando. Esta cirurgia de aneurisma no abdome é rara, é muito difíicil. Daí eu fico um pouco nervosa um pouco apreensiva, ficar aqui, eu queria ir pro quarto. De um lugar jogam pra outro, então você fica assim, um ioiô, jogada. E a cirurgia tem que ser feita. Ese o aneurisma rompe? Eu quero viver! Se fosse só um dedo quebrado, você não liga! Mas você sabe do teu caso, da gravidade do teu problema. Acha que amanhã vão me atender? Sábado? Domingo? Eu estou angustiada, triste [emocionada, chorou]. [...] Sem resposta sem informação. Poderiam dar mais atenção, conversar falar, informar (P.1).

Um paciente portador de aneurisma de aorta, principalmente se dissecante, requer observação e cuidado intensivo. 0 profissional de enfermagem deve monitorar 0 seu estado clínico, correlacionando os sinais e sintomas à doença a fim de evitar complicações. Além dos cuidados clínicos relacionados à doença, emoções fortes devem ser evitadas, pois provocam a alteração dos sinais vitais e precipitam complicações que podem ser fatais. ${ }^{15}$ No entanto, questiona-se: Com base no relato da participante anteriormente, esses cuidados estariam sendo considerados pela enfermagem?

Na maioria das realidades dos serviços de emergência, o quantitativo de recursos humanos é menor que o de recursos tecnológicos, e o quantitativo de pessoal da equipe de enfermagem para atender a demanda da população é menor que o de médicos em geral, seguido pela oferta de especialistas, cuja qualidade do cuidado decai proporcionalmente ao número da taxa de ocupação, sendo de até $300 \%$ em alguns serviços, onde muitos pacientes aguardam mais de 72 horas por um leito. ${ }^{16}$ Tais critérios não foram objetos deste estudo, entretanto a realidade do serviço estudado, pela observação das pesquisadoras, parece não diferir muito do exposto, o que poderia justificar, em parte, as insatisfações relatadas pelos participantes.

A equipe de enfermagem que atua em um serviço de emergência, independentemente das dificuldades vividas, necessita atentar para os cuidados específicos ao paciente crítico e proporcionar-Ihe um ambiente tranquilo, a fim de minimizar possíveis complicações e riscos à vida do ser que está sob sua responsabilidade. Sobretudo, importa estar atento ao outro, tendo, além da visão local, também a visão global do indivíduo, do ambiente, tendo em vista o cuidado multidimensional e complexo. ${ }^{4}$
A enfermagem deve oferecer ao outro um cuidado profissional e também humano, que contemple as necessidades mais específicas de cada indivíduo em sua totalidade. 0 cuidado de enfermagem requer, antes de tudo, a valorização da vida humana, embasado em elementos como a empatia, o respeito, amor, atenção, carinho, dignidade, comprometimento, dentre outros. Convém, na relação com o outro, contemplar suas expectativas e necessidades, visando à promoção do seu bemestar e à minimização de riscos que possam comprometer sua saúde.

Sendo uma das principais necessidades significadas pelos pacientes a da informação, entende-se que, para 0 favorecimento das práticas de cuidado, urge que sejam orientados acerca da sua problemática, contemplando o respeito à autonomia do ser enquanto cidadão, respeitando os preceitos da ética ${ }^{11}$ e estimulando 0 autocuidado pelo próprio sujeito. Por outro lado, segundo o pensamento complexo, ${ }^{4}$ o ser humano desenvolve a sua autonomia mediante a dependência do outro e de outras coisas, neste caso, da instituição e dos que se relacionam a esta, como os profissionais de enfermagem e da saúde em geral. Assim, ao serem contempladas suas dúvidas, estarão sendo respeitados o direito ao conhecimento no que diz respeito ao processo de hospitalização e tratamento e sua autonomia, relacionada ao cumprimento da ética profissional e à autonomia do homem como forma de ser.

\section{Comunicação como expressão de "não cuidado"}

A comunicação é classificada em verbal e não verbal. "Na verbal, faz-se uso das palavras por elas mesmas na relação entender e fazer-se entender; já a não verbal, é aquela que não envolve a verbalização por ela mesma"17:207. Na relação interpessoal a comunicação expressa pela linguagem não verbal facilita a compreensão entre os seres, cuja comunicação emitida por sinais não verbais, como a linguagem do corpo, o toque, a distância mantida entre os envolvidos etc. contribui para a identificação e o entendimento de aspectos peculiares em relação ao outro. ${ }^{17}$

Neste estudo, os participantes, em suas falas, explicitam que os profissionais de enfermagem e da saúde em geral comunicam em suas ações e atitudes - o não verbal pouco contato, qualificando o cuidado como mais mecânico do que humano, ou seja, denotando insensibilidade. A comunicação não verbal por meio do toque, do olhar que cuida; que integra os seres e representa o importar-se com o outro; que expressa preocupação, zelo, afeto, conforto, amor e carinho, está sendo pouco utilizada na relação do profissional com o paciente. Por sua vez, a comunicação verbal também apresenta falhas, como apontam as falas:

[...] eles nem olham [profissionais da enfermagem e saúde], porque hoje o modo de vida, a maneira de vida, as pessoas, hoje, nem olham pra quem tá do lado; não dão mais importância pro outro e vai se 
acostumando, até quem trabalha aqui [...] eles estão meio mecânicos. De tanto eles fazerem, eles acabam ficando meio insensíveis (P.1).

[...] Pouco contato, mais mecânico que humano, fazer só por fazer. Aconteceu comigo, eu tava mais estressada e uma delas [profissional de enfermagem] respondeu meio grossa, fria, e eu saí pra chorar! [...] Fica com o psicológico abalado, eu controlo bastante, sei que não to num hotel cinco estrelas, mas um pouco de respeito ébom! Agente percebe que o pessoal que trabalha no hospital, na saúde, não tem tanta culpa. Eles acabam ficando insensíveis [...]. Não adianta existir máquinas e as pessoas não se atualizarem. Colocar mais gente jovem. Quem tá aí é só pra se aposentar (P.2).

Entende-se que os profissionais de enfermagem precisam cultivar a comunicação não verbal, resgatando o uso do toque e do olhar como expressão de cuidado. 0 primeiro aproxima os seres por meio do contato humano, e o segundo denota a preocupação e o desvelo de um pelo outro, imprescindíveis em uma relação de cuidado, uma vez que a equipe de enfermagem necessita atentar para essas expressões e valorizá-las como um importante instrumento de aproximação e entendimento do outro ser.

A comunicação, chamada por alguns autores como 0 instrumento básico da terapêutica de enfermagem, com o desenvolvimento da profissão teve a sua utilização restringida pelo profissional na assistência ao paciente, cujo trabalho se tornou mais mecânico e impulsivo no cuidado físico do paciente e a comunicação menos efetiva. ${ }^{19}$ Ressalta-se, no entanto, a importância de o profissional de enfermagem estar atento ao tipo de comunicação estabelecida com o paciente, seja verbal, seja não verbal.

Os depoimentos também assinalam a pouca importância dada ao outro, à vida e à instituição onde estão alocados, situação que tem se tornado rotina no cotidiano das pessoas como forma de viver e se relacionar. A forma de comunicação pelos profissionais de enfermagem no ambiente da emergência aponta o pouco interesse pelo outro, inclusive manifestando, algumas vezes, um tratamento grosseiro, frio e insensível. Identifica-se, portanto, condição de "não cuidado" na relação do profissional com o ser hospitalizado em sua forma de expressão.

0 "não cuidado" a pacientes assistidos em instituições hospitalares revelado no estudo é entendido como um problema que acontece cotidianamente nas relações e inter-relações do processo de cuidar/cuidado, que pouco orgulha os profissionais da saúde pelos serviços oferecidos e remete à reflexão de que há muito a se fazer para melhorar a condição revelada. Essa responsabilidade é de todos os envolvidos no processo, para a garantia da cidadania e dos direitos enquanto seres cuidados. ${ }^{7}$
A saúde física fragilizada dos seres que vivificam uma experiência de atendimento e ou hospitalização em um serviço de emergência muitas vezes torna o estado emocional também frágil, sendo desejante que seus cuidadores estejam dotados de maior grau de sensibilidade para o atendimento das suas necessidades, inclusive das subjetivas. Naturalmente, a qualidade do cuidado e da relação entre profissionais e pacientes dependerá da capacidade em estabelecer relacionamentos interpessoais adequados às expectativas do outro. ${ }^{18}$

Os pacientes não culpam os profissionais pelas situações expostas. Em parte, justificam que o cansaço oriundo dos vários anos de profissão, dos que estão aguardando a aposentadoria, seria responsável pelo tratamento hostil e insensibilidade; assinalam ainda que cabe aos dirigentes da instituição prover o quadro de trabalhadores com profissionais mais jovens, promover e incentivar a atualização permanente dos demais.

Contudo, nenhum comportamento hostil e desrespeitoso pelos profissionais de enfermagem pode ser justificado, independente das razões que o motivaram ou motivam. É imperativo que as instituições tomem conhecimento acerca dos acontecimentos que ignoram o respeito à ética e a dignidade do cidadão, conduzindo seus profissionais à melhoria da qualidade da assistência, priorizando não apenas a qualidade dos recursos materiais, mas também dos recursos humanos.

Assevera-se que, apesar de os depoimentos apontarem condições de "não cuidado", sabe-se que as instituições de saúde, principalmente as públicas e os profissionais que nelas atuam, têm enfrentado algumas dificuldades, denunciadas inúmeras vezes pela mídia, dentre as quais a da superlotação das emergências, cujo efetivo de trabalhadores tem se tornado insuficiente para suprir a demanda da clientela. Não obstante, convém salientar que cabe à enfermagem uma postura que recupere a dignidade dos pacientes e da própria profissão nas suas múltiplas dimensões de cuidado, inclusive na forma de se comunicar com o outro.

Implica à equipe de enfermagem, inserida nas múltiplas dimensões, desenvolver suas ações/atividades de caráter assistencial, de gerenciamento e ensino, dentre outras, com 0 intuito de contribuir para o resgate e valorização do ser cuidado, o paciente, um ser digno de atenção, respeito, diálogo, comunicação, amor, afetividade, solidariedade e compreensão na sua totalidade e complexidade de ser.

A relação do profissional de enfermagem com o outropaciente e a compreensão entre estes podem ser potencializadas se for ampliada a capacidade de decodificar o não verbal, comunicando e entendendo adequadamente os sinais não verbais, os quais, mesmo sendo uma linguagem silenciosa, devem ser percebidos e valorizados. ${ }^{17}$ Sobretudo, deve-se considerar que as relações comunicacionais são complexas e não asseguram um foco de direção, mas sim de múltiplas interações, que comportam a dialógica ordem/desordem/ organização das complexas relações humanas, as quais são, ao 
mesmo tempo, antagônicas e complementares, experienciam as incertezas, os confrontos e contradições próprios do viver complexo. $^{4}$

\section{CONCLUSÕES}

0 estudo aponta a insatisfação e o descontentamento dos pacientes quanto às ações e atitudes da equipe de enfermagem, compreendidas como "não cuidado", tais como não informação, atenção e assistência devida; transferência de responsabilidade entre os profissionais; demasiado tempo para 0 atendimento de suas necessidades; não valorização dos sinais e comunicação não verbal como cuidado, como pouco contato, mais mecânico que humano; não prioridade de atendimento aos idosos; calma e respeito esgotados e, por vezes, tratamento grosseiro, frio e insensível.

Urge à enfermagem, como contribuição deste estudo, 0 avanço na forma de pensar e de agir a/na relação estabelecida com o outro e consigo mesma no espaço organizacional em saúde. Todos somos responsáveis pelo cuidado de/do outro ser, cuja condição exige que sejamos solidários e que as ações e atitudes cuidativas sejam comunicadas das mais diversas formas. Importa, para isso, a valorização das relações humanas como imprescindível ferramenta de cuidado.

A complexidade do cuidado, suas múltiplas dimensões e interfaces permitem entender que, no "não cuidado", está imbricado o cuidado que não é expresso e visível pelo paciente, ou seja, outras ações da enfermagem que asseguram a assistência, seus processos e contraprocessos da jornada de trabalho. A compreensão dessa organização complexa de cuidados continua sendo um grande desafio para reflexão, questionamentos, inquietações e busca da qualificação e aprimoramento para os profissionais da enfermagem, que têm como essência o cuidado humano.

As situações apresentadas nessas duas categorias nos remetem a reflexões sobre dilemas na tomada de decisão em situações nas quais as necessidades são crescentes e os recursos limitados, e sobre questões éticas referentes aos direitos dos pacientes e dos trabalhadores de enfermagem. São múltiplos os aspectos que nos tiram a possibilidade de compreensão dessas dimensões, que são relegadas às áreas de sombra nas organizações e nos serviços.

Cabe destacar que as categorias de "não cuidado" identificadas neste estudo provavelmente não estão isoladas do contexto social, político e econômico mais amplo no país, o que de certo modo é compreensível diante de um contexto com múltiplas demandas de ações imediatas, ficando estas em menor prioridade de execução. Todavia, importa aos dirigentes e profissionais de enfermagem e saúde dessas organizações e serviços um olhar atento e reflexivo acerca dos dados aqui apresentados, sendo oportuna a abertura para reflexão e discussão, tendo como foco o cuidado das relações humanas em saúde.
De outro modo, esse emaranhado de relações, interconexões, dimensões, requer que nós, trabalhadores da enfermagem, reconheçamos essa complexidade e sejamos compelidos a fortificar, a cada dia, nossa aptidão ou capacidade de reconhecer que, quanto mais os problemas se tornam multidimensionais, maior é a incapacidade para pensar a sua multidimensionalidade.

Afinal, seguimos nos questionando: que cuidado é esse?

É um cuidado fruto de um trabalho conflituoso, paradoxal, complexo, necessário, desafiante, envolvente, que requer persistência, atenção constante no sentido de buscar diariamente 0 engajamento da equipe de enfermagem na procura de soluções para as desordens, os imprevistos, as situações-problema que vivenciamos no nosso cotidiano laboral.

Essa pergunta segue em aberto diante da necessidade de busca dos contrapontos de vista do viver o trabalho da enfermagem num ambiente com estruturas e propriedades muito complexas. Portanto: que cuidado é esse?

\section{REFERÊNCIAS}

1. Wehbe G, Galvão CM. 0 enfermeiro de unidade de emergência de hospital privado: algumas considerações. Rev Latino-am Enfermagem. 2001 mar; 9(2): 86-90.

2. Conselho Federal de Medicina. Resolução n. 1451, de 10 de março de 1995 [página na internet]. Brasília (DF): Diário Oficial [da] Republica Federativa do Brasil, Poder Executivo; 1995 [citado 2009 maio 28]. Disponivel em: http://www.cremesp.org.br/library/modulos/legislacao/ versao_impressao.php?id=2989.

3. Ministério da Saúde (BR), Secretaria Executiva. Núcleo Técnico da Política Nacional de Humanização. Humaniza SUS: acolhimento com avaliação e classificação de risco: um paradigma ético-estético no fazer em saúde. Brasilia (DF); 2004.

4. Morin E. Introdução ao pensamento complexo. Porto Alegre (RS): Sulina; 2006.

5. Lovalho AF. Administração de serviços de saúde em urgências e emergências. 0 Mundo da Saúde 2004 abr/jun; 28(2): 160-71.

6. Hotvedt R, Thoner J, Wilskow AW, Ford HO. How urgent are emergency admissions? An evaluation of emergency admission to general hospitals in a Norwegian county. Intern J Technol Asses Health Care. 1999 0ct; 15(4): 699-708.

7. Padilha MICS, Maia AR, Vieira M, Machado C. Significados das práticas de não cuidados na visão dos clientes hospitalares. Rev Bras Enferm. 2004 nov/dez; 57(6): 724-28.

8. Alves PC, Lunardi VL, Lunardi GL, Lunardi Filho WD. A percepção das enfermeiras acerca da sua atuaçãa ante aos direitos dos clientes. Rev Esc Enferm USP. 2008 jun; $42(2)$ : 242-48. 
9. Ministério da Saúde (BR). Conselho Nacional de Saúde. Resolução n.196, de 10 de outubro de 1996: diretrizes e normas regulamentadoras de pesquisa envolvendo seres humanos. Brasília (DF); 1997.

10. Minayo CMS. 0 desafio do conhecimento: pesquisa qualitativa em saúde. $6^{a}$ ed. São Paulo (SP): Hucitec; 2006.

11.Conselho Federal de Enfermagem- COFEn. Código de Etica dos Profissionais de Enfermagem [página na Internet]. Portal do Cofen; 2007 [citado 2009 jan 16]. Disponível em: http://www.portalcofen.gov.br/2007/ materias.asp?ArticlelD=7323\&section $\mid \mathrm{D}=37$

12. Freitas GF, Oguisso T. Ocorrências éticas com profissionais de enfermagem: um estudo quantitativo. Rev Esc Enferm USP. 2008 mar; 42(1): 34-40.

13.. Ministério da Saúde (BR). Estatuto do Idoso. Brasília(DF); 2003.

14. Pontes APM, Cesso RGD, Oliveira DC, Gomes AMT. 0 princípio de universalidade do acesso aos serviços de saúde: o que pensam os usuários? Esc Anna Nery. 2009 jul/set; 13(3):500-07.

15. Morton PG, Fontaine DK, Hudak CM, Gallo BM. Cuidados críticos de enfermagem: uma abordagem holística. $8^{\mathrm{a}}$ ed. Rio de Janeiro (RJ): Guanabara Koogan; 2007.

16. O’Dwyer G, Matta IEA, Pepe VLE. Avaliação dos serviços hospitalares de emergência do estado do Rio de Janeiro. Cienc Saude Colet. 2008 set/ out; 13(5): 1637-648.

17. Silva MF; Silva MJP. A auto-estima e o não-verbal dos pacientes com queimaduras. Rev Esc Enferm USP. 2004 jun; 38(2): 206-16.

18. Hoga LAK. A dimensão subjetiva do profissional na humanização da assistência à saúde: uma reflexão. Rev Esc Enferm USP. 2004 mar; 38(1): 13-20. 